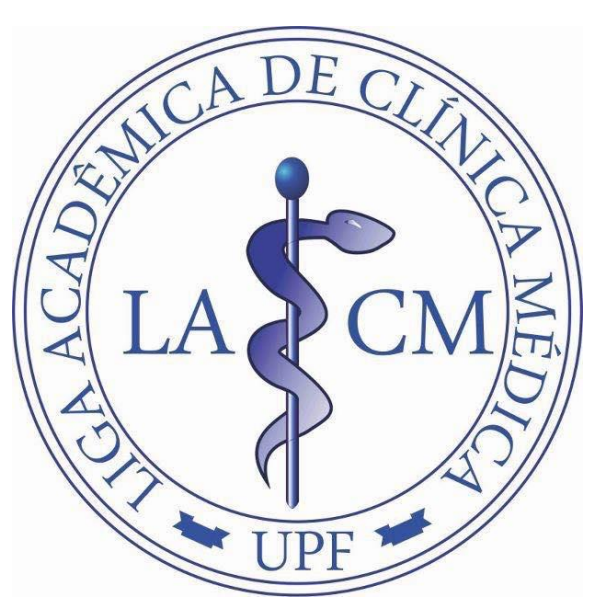

\title{
GRANULOMATOSE EOSINOFÍLICA COM POLIANGEÍTE E MONONEURITE MÚLTIPLA: UM RELATO DE CASO
}

Ana Claudia Kurmann ${ }^{1}$, Agnes Gabrielle Wagner ${ }^{1}$, Augusto Poloniato Gelain ${ }^{1}$, Gabriel de Carvalho Scortegagna ${ }^{1}$, Gabriela Gregory ${ }^{1}$, Jéssica Maldaner Lui ${ }^{1}$, João Vitor Dal Bosco Zaffari ${ }^{1}$, Luiza Mattos Volpi ${ }^{1}$, Mariana Mesko da Fonseca Lubbe ${ }^{1}$, Martina Souilljee Birck $^{1}$, Nicolle Surkamp ${ }^{1}$, Thamyze Mânica Martio ${ }^{1}$,Victor Antônio Kuiava ${ }^{1}$, Matheus Augusto Eisenreich ${ }^{2}$

${ }^{1}$ Acadêmicos de medicina da Universidade de Passo Fundo (UPF) ${ }^{2}$ Médico reumatologista e professor de Reumatologia da Universidade de Passo Fundo (UPF)

\section{INTRODUÇÃO}

A Granulomatose Eosinofílica com Poliangeíte (GEPA) é uma condição envolvendo asma, hipereosinofilia e vasculite necrotizante ${ }^{1}$. É uma doença rara, com prevalência de 10,7 a 14 casos por milhão de habitantes ${ }^{2}$. É classificada como vasculite associada aos anticorpos citoplasmáticos antineutrófilos (ANCA), presente em $40 \%$ dos $\operatorname{casos}^{2,3}$. A idade média de acometimento é aos 48 anos, sem preferência por raça ou $\mathrm{sexo}^{4}$. A sintomatologia é heterogênea e difere ao longo das fases da doença, sendo as neuropatias sinais comuns da fase eosinofílica ${ }^{2,5}$. O diagnóstico é clínico, baseado nos critérios do American College of Reumathology (ACR): asma, eosinófilos > 10\%, neuropatia, infiltrados pulmonares migratórios, alteração em seios paranasais e biópsia com eosinofilia extravascular ${ }^{5,6}$.

\section{OBJETIVOS}

O presente relato visa discutir o caso de paciente que apresentou mononeurite múltipla (MNM) como primeira manifestação de GEPA.

\section{RELATO DO CASO}

Paciente masculino, 31 anos, apresentou púrpuras em membros inferiores (MI), paresia e parestesia assimétricas, que evoluiu para membros superiores (MS), com piora progressiva. Apresentou poliartralgia, proteinúria, eosinofilia (56\%), VSG e PCR elevados, ANCA não reagente. A eletroneuromiografia (ENM) evidenciou MNM em MS e MI. Realizou biópsia de pele que apresentou dermatose eosinofílica com infiltrado eosinofílico perivascular, perianexial e intersticial. Em seu histórico possui colite isquêmica. Diagnosticado com GEPA, iniciou o tratamento através de pulsoterapia com metilprednisolona por 3 dias e ciclofosfamida intravenoso mensal. Após suspender inadvertidamente o tratamento, apresentou exacerbação grave da doença com crise asmática e cavitação pulmonar em ápice esquerdo, obtendo melhora após nova pulsoterapia com metilprednisolona e reinicio da prednisona oral.
Devido gravidade da doença optou-se por manutenção com rituximabe, azatioprina e prednisona.

\section{DISCUSSÃO}

A MNM é uma manifestação comum nos pacientes com GEPA e é causada pela inflamação da vasa nervorum, confirmada através de exames de $\mathrm{ENM}^{2-4}$. A positividade do ANCA é um fator que favorece essa condição, enquanto a sua ausência relaciona-se com casos de miocardite ${ }^{3,4}$. O caso apresentado difere-se por manifestar neuropatia sem a presença do anticorpo.

\section{CONCLUSÃO}

A GEPA é uma vasculite rara de pequenos e médios vasos associada ao ANCA. Sua clínica pode ser variada, sendo a MNM uma das manifestações mais comuns. O tratamento se dá através de corticoterapia e imunossupressores.

\section{REIERENCIAS}

1. Churg J, Strauss L. Allergic granulomatosis, allergic angiitis, and periarteritis nodosa. Am J Pathol 1951;27:277301

2. Greco A, et al, Churg-Strauss syndrome, Autoimmun Rev (2014), http://dx.doi.org/10.1016/j.autrev.2014.12.004

3. Cottin V. et al, Revisiting the systemic vasculitis in eosinophilic granulomatosis with polyangiitis (ChurgStrauss). A study of 157 patients by the Groupe d'Etudes et de Recherche sur les Maladies Orphelines Pulmonaires and the European Respiratory Society Taskforce on eosinophilic granulomatosis with polyangiitis (Churg-Strauss), Autoimmunity Reviews 16 (2017) 1-9

4. Mouthon L, et al., Diagnosis and classification of eosinophilic granulomatosis with polyangiitis (formerly named ChurgeStrauss syndrome), Journal of Autoimmunity (2014), http://dx.doi.org/10.1016/j.jaut.2014.01.018

5. Navarro-Mendonza E.P, Tobón G.J, Eosinophilic Granulomatosis With Polyangiitis: Newer Therapies, Current Rheumatology Reports (2018) 20:23

6. Masi AT, Hunder GG, Lie JT, et al. The American College of Rheumatology 1990 criteria for the classification of Churg-Strauss syndrome (allergic granulomatosis and angiitis). Arthritis Rheum 1990; 33: 1094-1100. 